..Revista da Faculdade de Direito-RFD-UERJ - Rio de Janeiro, n. 29, jun. 2016

\title{
DIÁLOGOS INTERCULTURAIS ENTRE O OCIDENTE E O ORIENTE: O DISCURSO OCIDENTAL COMO FORMA DE EXCLUSÃO DA CULTURA ÁRABE
}

\author{
INTERCULTURAL DIALOGUE BETWEEN THE WEST \\ AND THE MIDDLE EAST:
}

THE WEST SPEECH AS A WAY OF EXCLUSION OF THE ARAB CULTURE

Gabrielle Tesser Gugel $^{1}$

“As pessoas importam e cultura importa para as pessoas"
Anthony Appiah

RESUMO: O presente texto tem por objetivo uma reflexão sobre como o discurso dos Estados pan-europeus legitima a exclusão da importância política dos Estados árabes e promove meios para uniformização da sua cultura. Para isso, inicia-se a análise sobre as transformações ocorridas ao longo dos anos no modo com que o ocidente relaciona-se com o oriente, culminando com as recentes observações de Ana Paula Tostes e Judith Butler sobre o discurso ocidental, além de abordar a importância da biopolítica para essa reflexão. Recentemente as discussões envolvendo a universalização dos direitos humanos estão demonstrando a ocorrência de uma uniformização da cultura árabe devido a imposição da cultura ocidental, o que dificulta ainda mais a promoção de diálogos interculturais.

PALAVRAS-CHAVE: ocidente; árabe; diálogo intercultural.

ABSTRACT: This paper wants to reflect on how the discourse of pan-European States legitimizes the exclusion of the political importance of the Arab States and promotes ways to standardize their culture. For this, begins the analysis about the transformations than have occurred over the years in the way that the West relates to the east, culminating with the recent observations of Ana Paula Tostes and Judith Butler on the Western discourse, in addition to addressing the importance of biopolitics to this debate. Recently discussions involving the universalization of human rights are demonstrating the occurrence of a

\footnotetext{
${ }^{1}$ Mestre em Direito Público pela UNISINOS. Bacharel em Direito pela Universidade de Caxias do Sul. Advogada. Presidente da Associação Nacional dos Emigrados e Ex-emigrados das Américas e Austrália - Brasil. Email: gabitgugel@gmail.com
} 
standardization of Arab culture because the imposition of Western culture, which further complicates the promotion of the intercultural dialogue.

KEYWORDS: West; Arabic; intercultural dialogue.

\section{INTRODUÇÃO}

As transformações ocorridas no campo da política internacional, o insuficiente diálogo entre o ocidente e o oriente, o ataque às torres gêmeas no dia 11 de setembro de 2001, o conflito armado entre os Estados Unidos e o Iraque, a manutenção das penas de apedrejamento e mutilação no Oriente Médio, dentre outras incongruências da sociedade que continuam a emergir, criam um imbróglio nessa relação que há séculos não é de todo pacífica.

O presente texto tem por escopo analisar em que medida o discurso pan-europeu determina a exclusão da importância política dos Estados árabes, além de promover meios para uniformização da cultura árabe.

Para isso, inicialmente contextualiza-se o discurso dominante dos Estados ocidentais, para que nessa perspectiva se possam entender as atitudes eurocêntricas. Observa-se que, as transformações ocorridas no discurso ocidental são um reflexo do pensamento intelectual na Europa e, mais recentemente, do governo norte-americano. A biopolítica desenvolvida por Michel Foucault no seu livro Em defesa da sociedade e por Giorgio Agamben, principalmente no livro Homo sacer: o poder soberano e a vida nua I, ajuda a perceber o rumo tomado pelas intervenções ocidentais no Oriente Médio. Juntamente com esses autores, o presente trabalho possui como base teórica os textos das escritoras Ana Paula Tostes e Judith Butler, tendo em vista que ambas abordam questões nevrálgicas na relação sociedade ocidental/oriental.

Visando à promoção de diálogos interculturais procura-se avaliar a influência da teoria protetiva dos direitos humanos no mundo árabe, uma vez que a uniformização da cultura árabe é um dos principais problemas trazidos pela teoria que universaliza de forma errônea os direitos humanos, sem, atentar que a ideia de universal deveria proteger o pluralismo cultural e não sufocá-lo.

Procurar caminhos para desenvolver o diálogo cultural não é uma tarefa fácil, pois exige esforço de todos os participantes da conversa. De todo o modo, a adoção da hermenêutica diatópica defendida por Boaventura de Sousa Santos no seu texto Por uma 
concepção multicultural dos direitos humanos pode ser uma luz para a resolução desse conflito.

\section{O OLHAR OCIDENTAL: O DISCURSO POLÍTICO DOS ESTADOS OCIDENTAIS}

Não é por acaso que os conflitos entre o Ocidente e o Oriente continuam a ocorrer no século XXI. Ao longo da história, o pensamento oriental teve uma forte influência especialmente na Europa, entretanto, o modo como os árabes eram recebidos modificou-se ao longo dos anos.

Durante o medievo o poder da Igreja Católica solidificou-se na Europa Latina, dessa forma, propagou-se o entendimento de que aqueles que humilharam a religião da cruz (referindo-se aos muçulmanos, devido principalmente às Cruzadas) não deveriam ser bem recebidos, isso porque os árabes teriam vindo para o Ocidente por meio da violência, tal pensamento ramificou-se no imaginário medieval. O árabe que praticava o Islã era considerado herege, contudo a Igreja percebeu que era possível tolerá-lo, mesmo com a concorrência religiosa à Santa Fé em Roma, pois, através dos árabes o ocidente pode conhecer a filosofia e os conhecimentos científicos dos antigos. Apesar disso, mesmo durante o final da Idade Média, o conhecimento árabe era desprezado pelos intelectuais renascentistas, tendo em vista que os árabes somente eram necessários para que se pudesse conhecer a filosofia antiga, inclusive a influência de autores árabes nas obras literárias de grandes filósofos ocidentais, como Aristóteles e Santo Tomas de Aquino foi excluída do conhecimento intelectual. Ao passo dessa visão negativa ante o Islã, em um período mais próximo ao Renascimento, alguns estudiosos apaixonados pela cultura universal passaram a analisar os estudos árabes em uma cátedra do College de France (HIMMICH, 2004, p. 117-118; 122).

Foi durante o século XVII em meio a iluminismo, laicidade, racionalismo e anticlericalismo que o olhar ocidental sobre o Islã passou a considerá-lo como uma nova religião natural, realizando-se, assim, muitos estudos sobre os costumes e traduções dos textos escritos em língua árabe. Tal mudança na postura europeia ocorre principalmente porque a Turquia estava abrigando exilados perseguidos pelo cristianismo. Os intelectuais da época passaram então a considerar a superioridade do pensamento do Oriente árabe sobre o Ocidente, além de tornar Maomé um "legislador tolerante e sábio". As críticas que antes eram dirigidas ao fanatismo, despotismo e particularidades negativas aos olhos ocidentais deixam 
de ter relevância, pois passa a ser apreciado pelos europeus o erotismo oriental proveniente da Pérsia (HIMMICH, 2004, p. 123-124). Ou seja, enquanto no medievo ressaltavam-se as influências negativas no islã, na idade moderna há a preponderância das características positivas. Em ambos os períodos observa-se, ainda que com menor impacto, o pensamento árabe é visto como algo peculiar.

O movimento imperialista europeu durante o século XIX afirmou a diferença que havia entre o pensamento ocidental e o europeu, bem como a superioridade com que este se considerava em relação àquele. Assim, com o impacto do cientificismo, estudos físicos, evolucionismo biológico, o árabe "se transformou em um objeto específico, caracterizado na imagem do homo-islamicus", ao qual foram elaboram "estudos sobre a herança oriental em função de uma primazia religiosa, linguística ou étnica, podendo intervir nas questões do presente de forma desastrosa ou nociva". Os estudos de cunho evolucionista são comuns no século XIX. Com o advento do século XX, a postura de superioridade ocidental ganha força, a partir do movimento denominado eurocentrismo, ou seja, a crença na superioridade da cultura europeia sob as demais (movimento que se solidificou com a colonização e o imperialismo). Nesse período, ocorre a massiva colonização dos países muçulmanos pelos europeus (HIMMICH, 2004, p. 126-127). Atualmente, muitos Estados conseguiram conquistar a sua independência, entretanto, os rastros da colonização ocidental permanecem presentes, seja através da educação, língua, arquitetura.

Essa imposição ocidental criou uma educação eurocêntrica nos países muçulmanos, o que resulta na "negação das contribuições das civilizações não-ocidentais para a cultura humana e a alienação de suas novas gerações em relação a suas próprias sociedades e seus ambientes naturais". Isso porque as percepções não ocidentais são marginalizadas, sendo que o único paradigma válido é o ocidental. A história da humanidade é escrita como a história da Europa, sem considerar as culturas, ou seja, sem considerar o pluralismo. Aliás, esse é um dos fatores para que não se considere a importância das outras culturas, visto que rompe com a sua contribuição para a história da humanidade. Logo, "um chinês, um indiano, um muçulmano, um nativo-americano ou um estudante africano passaram por uma lavagem cerebral por parte deste pressuposto globalizado de que seus ancestrais não contribuíram com coisa alguma para história da humanidade", isso porque "não há lugar para Confúcio, Farabi, lbn Rushd, Liang Shu Ming, Iqbal, Ghandi ou Radhakrishnan nessa continuidade histórica" (DAVUTOGLU, 2004, p. 120-123). 
$\mathrm{O}$ ataque às torres gêmeas em Nova York, 11 de setembro de 2001, fez com que o ocidente passasse a rejeitar toda e qualquer forma de islã, de modo que o olhar ocidental não diferencia mais o "Islã do terror" do "islã do justo meio", sendo "este último, portador de valores autênticos tais como a tolerância e a paz e que repudia qualquer forma de violência, fanatismo e extremismo, recomendando, em tudo, moderação" (BENNANI, 2004, p. 133). Justamente a ideia desse islã do terror apoderou-se do imaginário ocidental nos últimos anos, ocasionando uma forte repressão e preconceito aos muçulmanos.

A partir desse ataque, os Estados Unidos mantêm como prisioneiros na sua base naval de Guantánamo, em Cuba, aproximadamente cento e sessenta e seis combatentes do Talibã sem lhes conceder o status de "prisioneiros de guerra", nos termos das Convenções de Genebra, assim, permanecem na prisão por prazo indeterminado e sem previsão de julgamento.

Determina o artigo $2^{\circ}$, das Convenções de Genebra que os direitos ali previstos serão aplicados em caso de guerra declarada ou de qualquer outro conflito armado que possa surgir entre duas ou mais das Altas Partes contratantes, mesmo se o estado de guerra não for reconhecido por uma delas. Além disso, o artigo 105 e seguintes determinam os direitos dos prisioneiros de guerra, tais como, ser assistido por um dos seus camaradas prisioneiros, de ser defendido por um advogado qualificado da sua escolha, de apresentar testemunhas e de recorrer.

Nesse caso, a justificativa do governo americano para não aplicação das Convenções seria que o termo prisioneiros de guerra ${ }^{2}$ incluiria, conforme determina o Documento, membros das forças armadas regulares que obedeçam a um governo ou uma autoridade não reconhecida pela potência detentora, entretanto, tal status que é negado não passou por julgamento de tribunal competente, mas simplesmente, advém da decisão do governo norteamericano. Por isso, as Convenções enquanto deveriam proteger àqueles que são detidos em combates, acabam por restringir a aplicação dos seus direitos àquela visão de guerra tradicional, nos moldes da Segunda Guerra Mundial. Diferenciando assim, o que seria considerada violência legítima e violência ilegítima, o primeiro caso seria o ataque armado empregado por Estado-nação, enquanto o segundo caso, seria a violência que advém de grupos que não estão ligados a um Estado-nação especificamente, tornando-os combatentes

\footnotetext{
${ }^{2} \mathrm{O}$ artigo $4^{\circ}$ das Convenções de Genebra determina quais são os capturados que se enquadram no status de prisioneiros de guerra, sendo que o artigo 105 em diante traz os direitos políticos que lhes são garantidos.
} 
ilegais (BUTLER, 2007, p. 225-226). Logo, de acordo com o entendimento norte-americano, a violência empregada pelos prisioneiros seria ilegítima, tendo em vista que não estariam vinculados a um Estado-nação, mas sim ao Talibã.

Além disso, com a promulgação do USA Patriot Act em 26 de novembro de 2001 os combatentes, também não possuem status de acusado, perante as leis dos Estados Unidos, "nem prisioneiros, nem acusados, mas apenas detainess, são objeto de uma pura dominação de fato, de uma detenção indeterminada não só no sentido temporal mas também quanto à sua natureza, porque totalmente fora da lei e do controle judiciário" (AGAMBEN, 2004, p. 14). Ou seja, permanecem na prisão em situação indefinida, pois não seriam nem os prisioneiros de guerra previstos nas Convenções de Genebra, nem os acusados de acordo com as leis norte-americanas.

Diante dessas atitudes do governo norte americano, Judith Butler (2007, p. 227-228) desmistifica o discurso ocidental, pois, este leva o cidadão a acreditar que o tratamento prestado aos prisioneiros seria correto, quando, na realidade, diferencia determinado grupo de seres humanos dos demais, ou seja, "sugere que a lei tem aplicabilidade limitada nesse âmbito, que não estamos em uma situação em que as regras acerca do tratamento humano possam ser estendidas universalmente, já que há exceções ao universal e aqui estamos lidando com a exceção". Tendo em vista a determinação dos prisioneiros como terroristas, o tratamento que lhes é dispensado não segue o Protocolo Internacional, pois os considera à margem da lei, no sentido de que o caráter do terror dispensaria a aplicação da lei.

Explica a autora que a classificação dos combatentes do Talibã, sejam eles vinculados ou não a Estados-nação, como terroristas também é uma forma de deslegitimar a violência empregada em nome de autoridades (no caso o Talibã) que o Estado detentor considera ilegítimo, pois quando se pressupõe que a violência deles não é vinculada a uma causa política, "ela é praticada, como se diz, por fanáticos, por extremistas que não defendem um ponto de vista e não fazem parte da comunidade humana". Logo, os prisioneiros de guerra de Estados-nação reconhecidos, recebem o tratamento condizente com tal status já outros não, como os combatentes do Talibã, assim, ocorre uma "desumanização — tratar alguns humanos como seres à margem do escopo da lei — se torna uma das táticas pelas quais uma civilização 'ocidental' supostamente distinta busca se definir em relação e por oposição a uma população compreendida, por definição, como ilegítima” (BUTLER, 2007, p. 229-230). 
..Revista da Faculdade de Direito-RFD-UERJ - Rio de Janeiro, n. 29, jun. 2016

A consideração de determinadas vidas humanas como ilegítimas faz com que o poder do soberano na biopolítica seja capaz de decidir sobre a vida indigna de ser vivida, ou seja, "na intersecção entre a decisão soberana sobre a vida maleável e a tarefa assumida de zelar pelo corpo biológico da nação, e assinala o ponto em que a biopolítica converte-se necessariamente em tanato-política", logo, a politização da vida torna-se uma forma de controle pelo soberano do corpo social, sendo que caberia a esse soberano a decisão sobre quais vidas merecem ser vividas e quais são indignas de tal privilégio (AGAMBEN, 2002, p. 148-149). Mesmo que, em um primeiro momento, a expressão vida indigna de ser vivida, tenha sido criada para justificar a eutanásia de pessoas deficientes ou impossibilitadas de manifestar a sua vontade, quando o governo norte-americano explica que o tratamento político dado aos combatentes do Talibã é peculiar, uma exceção ao que a legislação (tanto à americana, quanto às Convenções de Genebra), indiretamente, o mundo ocidental encontra-se diante de uma postura onde esses seres humanos que estão detidos, implicitamente, são considerados como vidas indignas.

Além disso, Giorgio Agamben (2004, p. 38; 78-79; 131) aponta para as transformações ocorridas na política e na contínua manutenção do Estado de Exceção como regra ao invés de, como o próprio nome já diz, ser de exceção, pois, quando o presidente Bush, após o 11 de setembro de 2001 intitulou-se "Commander in chief of the army [...] está procurando produzir uma situação em que a emergência se torne regra e em que a própria distinção entre a paz e a guerra (e entre guerra externa e guerra civil mundial) se torne impossível". A pertinência da noção do Estado de Exceção para entender a postura após o ataque às Torres Gêmeas ocorre porque as decisões que são tomadas no âmbito internacional estão sendo justificadas como medidas temporárias, entretanto, além de afetar todos os seres humanos, prorrogam-se por tempo indeterminado. Isso porque, desde a Primeira Guerra Mundial o estado de exceção continua a operar nos Estados Ocidentais, nesse contexto observa-se que o direito "pode ser, assim, impunemente eliminado e contestado por uma violência governamental que, ao ignorar no âmbito externo o direito internacional e produzir do âmbito interno um estado de exceção permanente, pretende, no entanto, ainda aplicar o direito". Porém, o estado de exceção é um estado que não está baseado no direito, apesar da tentativa de justificação de que seria para a proteção/manutenção da ordem jurídica que ele é instituído, o que se observa, na realidade, é que ele contraria a lei, tendo em vista que suspende a aplicação do direito. Assim, os atos que são cometidos pelos governantes durante 
o estado de exceção não estão vinculados ao sistema jurídico, como também não possuem força de lei, visto que, obviamente, são contrários à lei vigente. A teoria do autor demonstra que as medidas que são tomadas pelo Estado norte-americano, como no caso dos combatentes presos em Guantánamo, são contrárias aos regulamentos, tanto internos, quanto externos, que determinam a proteção dos direitos (ou ao menos preveem o julgamento) dos prisioneiros de guerra, logo, o discurso estadunidense apresenta-se com uma postura que não é jurídica, e direciona a ação humana a um "sistema jurídico transforma-se em uma máquina letal".

$\mathrm{Na}$ biopolítica a função da política deve basear-se no rompimento da ligação existente a violência instituída e o direito, tendo em vista que a política não deve ser confundida com o direito, logo, o poder executivo necessita do respeito à ordem jurídica vigente como forma de proteção tanto da vida como do direito (AGAMBEN, 2004, p. 133). Isso permite que se tente aos poucos desvincular o contínuo Estado de Exceção dos Estados modernos ocidentais.

As transformações ocorridas no Estado Moderno determinaram a emergência do biopoder, grosso modo, o Estado toma para si o poder de previdência, prolongamento da vida, de modo que passa a regulamentar novos mecanismos voltados a fazer com que a população ${ }^{3}$ prolongue sua vida. Nesse contexto, como forma de excluir àqueles que não fazem parte da população que o Estado considera digna, ele se utiliza do racismo, ou seja, o Estado moderno passa a diferenciar aqueles que devem morrer e aqueles que devem viver. $\mathrm{O}$ racismo assegura ao Estado, por meio do biopoder, a função assassina, a qual vai lhe dar o direito de matar. Essa morte engloba, tanto a morte direta, quanto mecanismos indiretos que a antecipem, ou mesmo, a morte política, a intolerância de uma raça (FOUCAULT, 2002, p. 304; 306). Conforme se percebe, o discurso ocidental é voltado para a morte política dos Estados Orientais, o que ocorre, por exemplo, quando deslegitima o discurso político dos combatentes do Talibã, não reconhecendo a influência política dos árabes para a sociedade.

Foi por meio do racismo que no século XIX os Estados europeus justificaram a colonização dos Estados do Oriente Médio e da América, uma vez que além do caráter de evolucionismo biológico (diferença das raças) que estava atrelado ao discurso político, o biopoder do Estado necessitava que o discurso legitimasse que o enfrentamento entre os povos. Assim, a resposta a esta necessidade foi o racismo. Ele está afora de um movimento

\footnotetext{
${ }^{3}$ O termo população é utilizado por Michel Foucault (2002, p. 292-293) na biopolítica para caracterizar o corpo múltiplo, com inúmeras cabeças, se não infinito pelos menos necessariamente numerável, para o qual as atividades de previdência do Estado estão voltadas, visto que a partir de então os fenômenos que são levados em consideração são os fenômenos coletivos.
} 
ideológico onde um Estado procura transferir as suas intolerâncias a outros indivíduos que atingiriam a sua população, isso porque é a forma de exteriorização do poder. Por isso, Foucault se pergunta "como se pode fazer um biopoder funcionar e ao mesmo tempo exercer os direitos da guerra, os direitos do assassínio e da função da morte, senão passando pelo racismo?", esse problema segundo o autor continua a ser problema, (FOUCAULT, 2002, p. $307 ; 309 ; 315)$ de todo o modo, é importante observar que, seja através da colonização dos países muçulmanos, ou mesmo da intolerância que os imigrantes árabes sofrem nos Estados Ocidentais, o racismo torna-se um mecanismo para que o discurso voltado ao biopoder seja compreendido e aceito pela sociedade.

Ana Paula Tostes (2009, p. 339; 355) publicou em 2009 uma pesquisa que realizou na Europa, onde se tem notado um crescimento gradativo dos partidos de extrema direita, cujas pautas apresentam propostas contrárias ao processo de integração da União Europeia e xenofóbicas, em oposição ao fluxo imigratório muçulmano. Nessas pautas políticas observase a "politização de novos temas, como imigração e identidade, ao mesmo tempo que a defesa de valores e crenças, e a preocupação com temas como cultura, soberania e segurança entraram fortemente nas agendas políticas do fim do século XX", ou seja, está presente um novo populismo, pois os partidos defendem a queda dos direitos pluralistas, sem guerra, ou golpe de Estado, mas sim com a ideia de criar preferencias para determinados cidadãos europeus (não-muçulmanos), enquanto os imigrantes não são aceitos, mas sim tolerados.

Segundo os partidos de extrema direita a crescente imigração teria ocasionado o crescimento da violência, desemprego, déficit no desenvolvimento econômico. Entretanto, constatou a autora nessa pesquisa que as sociedades menos afetadas pelos problemas sociais acima referidos são aquelas que mais votam nos partidos de extrema direita, o que contesta esse discurso dos partidos xenofóbicos. Ainda, nos países onde os partidos de extrema direita encontram suporte, seriam eles Alemanha, Áustria, Bélgica, Dinamarca, Finlândia, França, Grécia, Holanda, Itália, Luxemburgo, Reino Unido, observou-se a diminuição dos crimes de furto, enquanto que aumentaram os crimes de ódio. Logo, ao contrário do discurso dominante dos partidos de extrema direita, usado para convencer os cidadãos europeus, os países cujo fluxo imigratório seja elevado demonstram um menor suporte à agenda xenofóbica. Por isso, a autora conclui que há um ressentimento na Europa com relação à integração política e econômica pretendida, bem como no tocante à diminuição das diferenças entre as diversas culturas que emergem no solo europeu (TOSTES, 2009, p. 351; 361-362; 364). O texto da 
autora, aliado à pesquisa empírica por ela realizada, auxilia a entender como o contexto político europeu está tolerando a presença do imigrante muçulmano, usa-se a palavra tolerar, porque não se observa uma atitude para integrar o árabe na sociedade europeia.

Conforme se percebe a partir dos textos de Ana Paula Tostes e Judith Butler o discurso empregado pelos Estados ocidentais não ocorre ao acaso, uma vez que determina o modo como a relação conflituosa ocidente-oriente influencia na necessidade de que o pensamento ocidental/europeu seja propagado por todos os Estados, sem que se atente ao relativismo cultural.

\section{O OLHAR ÁRABE: PROMOVENDO DIÁLOGOS INTERCULTURAIS}

Os séculos XIX e XX foram responsáveis por grandes mudanças nos Estados muçulmanos. As diferentes ideias e bem estar material dos Estados Ocidentais fizeram com que a tradição muçulmana cedesse espaço à modernização e inserção na sociedade árabe de características ocidentais. ${ }^{4} \mathrm{O}$ direito muçulmano tomou essa influência e em diversos Estados foram introduzidos ramos completamente novos, como trabalhista, criminal, comercial, entre outros, entretanto, permanecem estáveis as regras quanto ao estatuto pessoal, o qual engloba as matérias de família, sucessões e capacidade. Com relação a estas matérias de estatuto pessoal ocorre a sua codificação, de modo a sistematizar o Direito, característica que até então não estava presente no Direito muçulmano, visto que era claramente ligado à tradição religiosa, além da introdução de matérias que não estavam previstas no estatuto. Jurisdições especiais de cunho religioso que eram encarregadas de aplicar o direito estão sendo substituídas por tribunais encarregados da análise dos códigos (DAVID, 1996, p. 427-430). Por isso, a sedução pelo modo de vida ocidental e o discurso político aos poucos estão uniformizando o modo de vida muçulmano.

Através da globalização, a uniformização da cultura árabe alcança novas fronteiras, pois é através dela que o uniforme propaga-se despercebido entre diferenças culturas, porém,

\footnotetext{
${ }^{4}$ Explica Voltaire Schilling (2003, p. 79-80) sobre a mudança ocorrida no modo de vida árabe que "quando os cobiçosos homens do petróleo da Europa e do Texas lá [refere-se o autor ao Oriente Médio] puseram os pés, no correr do século XX, disparando atrás de concessões e facilidades, entrando nas tendas dos mandões árabes com as mãos cheias de dinheiro, não fizeram nenhuma questão de que seus parceiros comerciais muçulmanos imitasses as liberais instituições políticas do Ocidente. Os xeques, com os bolsos repletos, entregaram-se então aos prazeres da vida. Carrões, mulheres, cassino, diamantes e rubis, aluguéis de hotéis inteiros nas principais capitais europeias ou em Las Vegas passaram a ser a única razão de existir."
} 
faz isso se passando por universal. ${ }^{5}$ Percebe-se que o uniforme impõe os seus modelos, sem parecer fazê-lo, sendo que não o faz por meio do direito, mas sim, de diversas mídias, distribuições de livros pelo mundo, telejornais de todos os Estados que são controlados por grupo de noticiais ocidental. Assim, ao tomar o universal com o uniforme, encontramos uma das maiores barreiras no diálogo intercultultural, mas também a sua utilidade, para criticar a universalidade distorcida que o mundo pan-europeu defende pois "perdemos ao mesmo tempo o que constitui a ajuda - que não seja apenas preservadora ou museológica - da diversidade das culturas; bem como o plano - que não seja apenas de imitação ou de assimilação - no qual elas poderiam se encontrar" (JULLIEN, 2009, p. 32-34).

Da mesma forma, para Boaventura de Sousa Santos “a globalização é o processo pelo qual determinada condição ou entidade local estende a sua influência a todo o globo e, ao fazê-lo, desenvolve a capacidade de designar como local outra condição social ou entidade rival". O autor define quatro processos de globalização, cuja importância reflete diante do multiculturalismo: localismo globalizado, ocorre quando um fenômeno local globaliza-se com sucesso, como as redes de fast food; globalismo localizado são impactos sofridos em razão de valores transnacionais introduzidos em uma cultura, que desestruturam as condições locais; cosmopolitismo são os movimentos que lutam contra as exclusões culturais e discriminações trazidas pelo localismo globalizado e globalismo localizado, seria uma espécie de solidariedade para preservação das culturas, diante da globalização; temas que envolvam o patrimônio comum da humanidade, seriam as questões que envolvem toda a humanidades e por isso precisam ser protegidas e respeitadas (SANTOS, 2004, p. 246-249). Conforme se observa, esses dois últimos processos referidos pelo autor entram em conflito com os dois primeiros e são meios para impedir a uniformização.

Após a Segunda Guerra Mundial ganhou força no pensamento europeu a defesa pelos direitos humanos, tal noção aliada ao eurocentrismo ocasiona uma busca pela propagação de tais direitos pelo mundo árabe. Importante observar que não se considera uma característica negativa a proteção dos direitos humanos nos países muçulmanos, o que se critica é quando

\footnotetext{
${ }^{5}$ É imponte explicar o sentido que o termo universal abarca para François Jullien (2009, p. 29-30), pois o autor diferencia-o do conceito de uniforme e de comum. A noção de universal, via de regra, é confundida com a de uniforme, ocorre que este, ao contrário daquele, não busca proteger o multiculturalismo, na realidade, o que faz é copiar uma cultura em face de outra, pois, "enquanto o universal é 'voltado' para o Um - uni-versus - e traduz uma aspiração a seu respeito, o uniforme não é. Desse um, senão uma repetição estéril”. A uniformidade, ao longo dos anos, esteve presente em muitos dos discursos daqueles que "levam" os direitos humanos e democracia para outros países, ou seja, erroneamente o uniforme apresenta-se como universal.
} 
tal noção é porta de entrada para uma uniformização da cultura árabe. Com a Declaração Universal dos Direitos do Homem, e sua consequente ratificação pelos países pertencentes às Nações Unidas, os países ocidentais tem-se fundamentado nas suas disposições de universalidade para impor suas ideias em Estados do Oriente Médio.

Para explicar essa situação, Wallerstein (2007, p. 26-27) demonstra que no ocidente, especialmente na Europa e países americanos, o universalismo tem sido levantado como justificação para as políticas desses países sobre aqueles não considerados desenvolvidos ${ }^{6}$, nesse caso fala-se em propagação de valores universais. O autor refere que os líderes apelam a três justificativas para defender o universalismo: a política seguida pelos líderes do mundo pan-europeu promove os direitos humanos e a democracia; apesar do multiculturalismo, a civilização ocidental é considerada superior às demais, bem como detentora das verdades universais, tanto que firmou uma Declaração que se intitula Universal; a última leva em consideração a condição econômica, no sentido de que não há como agir, senão de acordo com a modelo neoliberal. Por isso, Wallerstein chama o universalismo defendido pelo mundo pan-europeu como universalismo europeu, pois apesar da fachada bonita que ele aparenta, não passa de uma forma de manter a hegemonia do pensamento europeu, o sistema de mundo

\footnotetext{
${ }^{6}$ Nos discursos de George W. Bush para justificar a invasão no Afeganistão e Iraque, a missão da América seria levar a democracia (utilizada claramente como um conceito universal, aparentemente o único sistema político considerado justo pelo ocidente) a esses países, por isso seguem alguns trechos dos seus discursos: "History has called America and our allies to action, and it is both our responsibility and our privilege to fight freedom's fight. (...) And we have a great opportunity during this time of war to lead the world toward the values that will bring lasting peace (George W. Bush, State of the Union, 2002)"; "History has called our Nation into action. History has placed a great challenge before us: Will America, with our unique position and power, blink in the face of terror, or will we lead to a freer, more civilized world? There's only one answer: This great country will lead the world to safety, security, peace, and freedom (George W. Bush, Address to the Nation on the Proposed Department of Homeland Security, June 2002)"; "Tomorrow is September the 12th. A milestone is passed, and a mission goes on. Be confident. Our country is strong, and our cause is even larger than our country. Ours is the cause of human dignity, freedom guided by conscience and guarded by peace. This ideal of America is the hope of all mankind" (George W. Bush, Address to the Nation on the Anniversary of the Terrorist Attacks of September 11, from Ellis Island, New York, Septemper 11, 2002). No discurso de posse do segundo mandado presidencial George W. Bush refere que vai terminar o seu trabalho histórico democrático: "And above all, we will finish the historic work of democracy in Afghanistan and Iraq so those nations can light the way for others and help transform a troubled part of the world. America is a nation with a mission, and that mission comes from our most basic beliefs. We have no desire to dominate, no ambitions of empire. Our aim is a democratic peace, a peace founded upon the dignity and rights of every man and woman. America acts in this cause with friends and allies at our side, yet we understand our special calling: This great Republic will lead the cause of freedom (George W. Bush, State of the Union, 2004)"; "Across the generations, we have proclaimed the imperative of self-government, because no one is fit to be a master and no one deserves to be a slave. Advancing these ideals is the mission that created our Nation. It is the honorable achievement of our fathers. Now, it is the urgent requirement of our Nation's security and the calling of our time (George W. Bush, Inaugural Address, 2005)" (SANTOS, 2010, p. 158-191).
} 
não-democrático e sistema de mundo e as desigualdades sociais, defendendo como um caminho contrário a esse pensamento: o universalismo universal.

Partindo dessa perspectiva do universalismo, importante destacar que para o relativismo cultural, "a pretensão de universalidade desses instrumentos [a autora refere-se aos instrumentos internacionais de proteção aos direitos humanos] simboliza a arrogância do imperialismo cultural do mundo ocidental, que tenta universalizar suas próprias crenças", sugerindo, por óbvio que essa concepção universal, na realidade é a imposição de um modelo ocidental, que acaba por violar o multiculturalismo. De outro modo, os defensores do universalismo dos direitos humanos afirmam que a posição relativista "revela o esforço em justificar graves casos de violações dos direitos humanos que, a partir do sofisticado argumento do relativismo cultural, ficariam imunes ao controle da comunidade internacional", ou seja, os Estados firmam instrumentos internacionais, os quais permitem um controle pela comunidade internacional dos atos que transgridam os direitos humanos, porque o respeito à dignidade humana deve ser observado na sociedade contemporânea, sendo que o descumprimento dos Tratados merece uma punição ao Estado infrator (PIOVESAN, 2004, p. 62). Independente da cultura que diferencia o oriente do ocidente, é importante observar que existem necessidades que são iguais em todas as culturas, haja vista que a natureza humana impera e identifica aos outros como seus semelhantes (BARRETO, 2010, p. 239-40) Afinal, os seres humanos pertencem à comunidade humana. $\mathrm{O}$ que pode ser diferente é o sistema de crenças, ou seja, o modo como determinado fato é valorizado pela comunidade. ${ }^{7}$ Tanto a cultura árabe, quanto a ocidental possuem o seu sistema de crenças, a dignidade humana, por exemplo, está presente em ambas, contudo, a diferença está na forma como ela é concebida.

Especialmente no campo da antropologia é possível observar e compreender o comportamento de cada cultura, dentro de cada contexto social e comunitário, por isso as concepções de correto e incorreto não são as mesmas em todas as culturas, inclusive para

\footnotetext{
${ }^{7}$ Para entender melhor essa afirmação traz-se o exemplo de James Rachels (2006, p. 23-4) ao apontar que as culturas não são tão diferentes quanto parecem: "considere uma cultura na qual as pessoas acreditam que é errado comer carne de vaca. Esta pode até ser uma cultura pobre, em que não há comida suficiente; mesmo assim, as vacas não serão tocadas. Uma sociedade como esta parece possuir valores muito diferentes dos nossos. Mas será que realmente possui? Não perguntamos ainda o porquê de não comerem carne de vaca. Suponha que haja uma crença de que após a morte as almas das pessoas habitem os corpos dos animais, especialmente os das vacas; assim, uma vaca pode ser a avó de alguém. Agora, devemos dizer que seus valores são diferentes dos nossos? Não, a diferença não está aí. A diferença está no nosso sistema de crenças, não em nossos valores. Concordamos com o fato de que não devemos comer a carne de nossa avó e simplesmente discordamos sobre o fato de que a vaca é (ou poderia ser) nossa avó".
} 
James Rachels "se assumirmos que nossas ideias éticas serão compartilhadas por todas as pessoas em todos os tempos, estaremos sendo ingênuos" (RACHELS, 2006, p. 17-8). É justamente por isso, que a postura ética diante do relativismo cultural demanda analisar detalhadamente os costumes, sistema de crenças e a moralidade de cada cultura, bem como se tal moralidade pode ser considerada objetivamente plausível. Não se pode ser ingênuo diante do relativismo cultural, pois é fato que ele existe, basta observar os diversos sistemas de crenças e culturas que estão presentes em cada cultura, logo, a necessidade de respeito e diálogo impera.

Diante do multiculturalismo e da ideia do universalismo dos direitos humanos e sua promoção entre os povos, o universalismo universal proposto por Wallerstein fortalece a ideia de que as noções que hoje são defendidas na realidade promovem o pensamento europeu, não dando espaço às demais culturas, por isso esse universalismo é impar, pois, "recusa as caracterizações essencialistas da realidade social; historiza tanto o universal quanto o particular, reunifica os lados ditos científico e humanístico em uma epistemologia", nesse caso para que o universalismo não seja domínio dos cientistas, "e permite-nos ver com olhos extremamente clínicos todas as justificativas de 'intervenção' dos poderosos contra os fracos” (WALLERSTEIN, 2007, p. 118).

No contexto do multiculturalismo, para que os direitos humanos, justamente não violem os direitos de outras culturas, precisam ser percebidos como construção histórica, e não como manifestação abstrata, ditada unilateralmente por determinada cultura. Por isso, a teoria que se formula sobre os direitos humanos deve observar as particularidades das outras culturas. Tal teoria apresenta dois tipos de análise, a primeira seria jurídica, visando a apreciação de todo o conjunto de tratados internacionais, e dos mecanismos que garantam a efetivação dos direitos fundamentais, no plano nacional e internacional. A segunda análise diz respeito ao fundamento dos direitos humanos, tanto na perspectiva filosófica, quanto política. Ambos os níveis de reflexão são importantes, pois somente será possível a sua eficácia, se os Estados possuírem mecanismos para sua promoção, além do que é preciso que estes direitos sejam reconhecidos pela sociedade (BARRETO, 2010, p. 235-6). É por isso que toda a discussão acerca do multiculturalismo encontra certos empecilhos quando do reconhecimento da Declaração Universal dos Direitos Humanos, de 1948 e necessita-se que se explore melhor essa construção histórica dos direitos humanos. 
Ao contrário da noção universalista evocada pela Declaração, o que o universal realmente busca é a proteção do singular, ou melhor, do sistema de crença de cada cultura. Pode-se afirmar que os direitos humanos até então foram impostos pelo imperialismo europeu, porém a ideia de que os direitos humanos são somente àqueles previstos no Tratado Internacional europeu é uma contradição à própria ideia de universalidade dos direitos humanos (JULLIEN, 2009, p. 28). Afinal, se são direitos humanos são passíveis de proteção em favor dos seres humanos. De qualquer forma, o que se questiona é até que ponto sob o amparo dos direitos humanos, vem ocorrendo uma homogeneização da cultura árabe. Além do que, como essa legitimidade de protetor dos direitos humanos, autonomeada pelo mundo pan-europeu demonstra uma visão que superioridade que a cultura ocidental tem de si mesma, apesar de que com o pós-modernidade e a sociedade de risco, muitos paradigmas construídos na modernidade estão ruindo.

A promoção de diálogos interculturais entre o ocidente e o oriente necessita estar pautada em uma visão que reconheça a incompletude de cada cultura. Para Boaventura de Sousa Santos (2004, p. 256-257; 259) o diálogo seria possível por meio de uma hermenêutica diatópica entre os topoi de cada cultura, ou seja, cada cultura possui fundamentos que são fortes, incontestáveis para aqueles que estão inseridos nessa realidade. No caso da cultura ocidental um topoi seria a noção de direitos humanos, enquanto, na cultura islâmica, o umma: "comunidade étnica, linguística ou religiosa de pessoas que são o objecto do plano divino de salvação". Assim, em uma hermenêutica diatópica, ambas as culturas necessitam adotar o entendimento de que seus topoi, apesar de fortes, não são completos, partindo-se para um diálogo que, nesse contexto, não possui o objetivo de completá-las, mas sim compreender mutuamente a outra cultura, e consequentemente, ampliar a visão sobre si mesma. Isso é importante porque os indivíduos que estão inseridos em determinado topois não conseguem enxergar essas incompletudes próprias do sistema, desse modo, o ponto de vista de quem está de fora dele traz uma diferente forma de analisar a cultura, e ao mesmo tempo, permite o diálogo.

Do ponto de vista do umma os direitos humanos apresentam incompletude porque não trazem a noção de solidariedade e cooperação, tão importante para a cultura muçulmana como forma de crescimento. Enquanto que partindo da perspectiva dos direitos humanos a umma eleva muito os deveres dos indivíduos, pouco referindo sobre os seus direitos, sendo que justamente por pensar na ideia do coletivo releva as disparidades e preconceitos entre homens 
e mulheres e entre muçulmanos e não-muçulmanos. ${ }^{8}$ Logo, na cultura ocidental existe uma predominância do individualismo, o que cria uma dificuldade quando da proteção de direitos coletivos e difusos, enquanto que como esse individualismo não está presente na cultura árabe, as disparidades entre os sujeitos são significativas. Conforme se percebe, as incompletudes encontram-se em ambos os sistemas, sendo, entretanto, ponto de partida para a realização do diálogo. As relações entre o sistema islâmico e os direitos humanos não está bem definida pela doutrina, existem duas correntes de pensamento que discutem a possibilidade da proteção dos direitos humanos na cultura árabe, de um lado estão os absolutistas ou fundamentalistas e de outro, os modernistas ou secularistas. Para a primeira corrente o sistema jurídico da char'ia, deve ser aplicado na sua totalidade pelos muçulmanos, tendo em vista que como existiriam conflitos irreconciliáveis entre a concepção ocidental de direitos humanos e a char'ia, esta deve prevalecer. Isso determina a exclusão dos nãomuçulmanos do sistema jurídico muçulmano, uma vez que o Estado muçulmano somente é cabível dentre os muçulmanos. A segunda corrente separa a noção de religiosidade/espiritualidade e política, ou seja, defende que as decisões decorrentes da aplicação dos direitos humanos são de natureza politica e não religiosa, sendo possível que as sociedades determinem de que forma ocorrerá a proteção dos direitos humanos, no sentido de regulação jurídica (SANTOS, 2004, p. 260-261).

Assim, Boaventura de Sousa Santos propõe o caminho explicado por An-na'im, no sentido de que é preciso analisar quais são os fundamentos da dignidade humana em cada sistema cultural, para conciliar os pontos de conflito entre elas. Segundo o autor, o principal problema na cultura islâmica seria essa desigualdade entre os sexos e entre muçulmanos e não-muçulmanos, o que acarreta uma grande dificuldade para a proteção dessa cultura. Isso ocorre principalmente porque o sistema jurídico muçulmano está baseado no entendimento formulado pelos doutores da lei nos séculos VIII e IX, nesse período a construção do "outro" não foi realizada. No Corão e na Suna existem dois níveis históricos, um período chamado de Meca Antiga, no qual há “a mensagem eterna e fundamental do Islão, que sublinha a

\footnotetext{
${ }^{8}$ Isso ocorre porque o direito muçulmano não é um ramo autônomo da ciência, é apenas uma das faces da religião do islã. Esta comporta, por um lado, uma teologia que fixa os dogmas e determina aquilo em que o muçulmano deve crer; comporta, por um lado, uma parte, o char' ou char'ia, isto é, "o caminho a seguir", constitui o que se chama de direito muçulmano. Ele está centrado sobre a ideia de obrigações que incumbem ao homem e não a seus direitos. O princípio religioso sobre o qual repousa torna-se inaplicável quando não se está entre muçulmanos. (DAVID, René. Os grandes sistemas do direito contemporâneo. 3. ed. São Paulo: Martins Fontes, 1996. p. 408).
} 
dignidade inerente a todos os seres humanos, independentemente de sexo, religião ou raça", e outro clamado de Medina, ocorrida no século VII e que fundamentou orientação jurídica para a realização do entendimento formulado pelos muçulmanos e que são seguidas até hoje. Como a mensagem decorrente da Meca Antiga foi considerada avançada demais para a época, foi suspensa, porém atualmente seria o período em poderia voltar a ser aplicada por meio da Reforma Islâmica, para quem sabe permitir esse diálogo entre ambas as culturas, uma vez que a dignidade humana estaria implícita nessa forma de pensamento. Logo, a hermenêutica diatópica "exige uma produção de conhecimento coletiva, participativa, interativa, intersubjetiva e reticular, uma produção baseada em trocas cognitivas e afetivas que avançam através do aprofundamento da reciprocidade" entre a cultura islâmica e a ocidental, para que não ocorra uma sobreposição entre elas (SANTOS, 2004, p. 262-264). O exercício da hermenêutica permite que as discussões ocorram no âmbito dos topoi, como forma de preservação de ambas as culturas, porque eles representam o ponto forte de cada uma delas.

As relações entre o ocidente e o oriente apesar de ocorrerem há séculos, não foram capazes de estabelecer um diálogo para uma busca de soluções entre as divergências existentes, de todo o modo, ambos compartilham "muitos valores universais, tais como, a justiça, a liberdade, a igualdade ou a dignidade humana", as diferenças estarão presentes no sistema de crenças. Por isso, "o diálogo entre culturas deve ser integrado ao diálogo político e econômico, já que as fraturas e divergências não são próprias do terreno religioso. As linhas de fratura devem-se à injustiça, às disparidades econômicas, à pobreza, ao grau de exercício da democracia" (BENNANI,

2004, p. 136).

Evidente que o caminho para esse diálogo é sinuoso, entretanto a dificuldade que o Estado Ocidental possui em relacionar-se com os árabes cria situações em que a dignidade humana dos muçulmanos não é respeitada pela civilização ocidental, sendo que esta sequer percebe que isso ocorre, porque o discurso que é empregado embaça a sua visão. Esse é o caso dos combatentes do Talibã que estão detidos em Guantánamo.

\section{CONSIDERAÇÕES FINAIS}

Conforme restou evidenciado, a biopolítica, por meio do racismo, vem sendo utilizada para a projeção do discurso dominador evidenciado pelos Estados ocidentais. Apesar de todas 
as tentativas de integração política dos muçulmanos no discurso político, o que prevalece é o conflito e suposta superioridade da cultura europeia secularista. A contínua e indeterminada manutenção do Estado Exceção dificulta o diálogo e faz com que o Estado ocidental não respeite as regras por ele criadas, especialmente aquelas constantes em tratados internacionais, justamente para garantir os direitos de todos os indivíduos,

O que ocorre em Guantánamo demonstra que o diálogo é fundamental e não pode ser continuamente adiado, tendo em vista que quanto mais se espera, mais a dignidade humana é violada.

Manifesto que ao longo dos anos o ocidente tem se colocado como o sujeito da história, entretanto, com a pós-modernidade e a ideia da sociedade de risco, a própria sociedade ocidental se encontra em crise, ou seja, sofrendo os reflexos dos seus atos.

É preciso ficar atento à padronização imposta pela uniformização dos direitos humanos, tendo em vista que isso prejudica o multiculturalismo e impõe valores culturais do povo ocidental sobre o muçulmano. A crescente ocidentalização do mundo árabe é um exemplo que a importação de valores está transformando o modo de vida muçulmano. A uniformização não promove a universalização dos direitos humanos, muito antes, pelo contrário, viola os direitos humanos das demais culturas. Impor padrões considerados aceitáveis para as culturas desenvolvidas, em detrimento de culturas consideradas subdesenvolvidas, propaga a ideia da uniformização e vai contra a politica de reconhecimento dessa identidade humana.

É possível garantir a diversidade cultural do mundo árabe, conforme demonstra o multiculturalismo, enquanto se protegem os direitos humanos, tendo em vista que o que se busca é a proteção do ser humano. Há que se atentar: não existem culturas inferiores ou superiores às demais, o que existem são sistemas de crenças diversos, que necessitam de proteção e respeito. Porém, não se pode perder uma reflexão crítica acerca das diversas culturas, de modo a analisar se determinados costumes realmente são necessários e se de fato fazem parte do sistema de crenças da sociedade em questão.

Por isso, devem ser fortalecidos os diálogos interculturais, somente assim é possível colocar-se no lugar do outro, olhar através de outras janelas, para então promover as alterações necessárias diante das incompletudes de cada sistema de crenças. A hermenêutica diatópica proposta por Boaventura de Sousa Santos promove uma perspectiva de diálogo, onde por meio da Reforma Islâmica e da ideia ocidental de direitos humanos seria possível 
encontrar um meio de agregar, de um lado, a proteção de direitos coletivos na cultura ocidental, e de outro, a proteção do indivíduo enquanto sujeito de direitos, na cultura muçulmana, independente de sexo e opção religiosa.

Claro que o caminho é longo, tendo em vista que o consenso é uma tarefa árdua, contudo não se pode fraquejar, senão a combinação entre o contínuo Estado de Exceção e uma atitude não tão agradável de Dr. Strangelove ${ }^{9}$ continuará a criar conflitos, ao invés de diálogos, conflitos esses letais.

\section{REFERÊNCIAS BIBLIOGRÁFICAS}

AGAMBEN, Giorgio. Homo sacer: o poder soberano e a vida nua I. Tradução por Henrique Burigo. Belo Horizonte: Editora UFMG, 2002.

AGAMBEN, Giorgio. Estado de exceção. São Paulo: Boitempo, 2004.

BALDI, César Augusto Baldi (Org.). Direitos humanos na sociedade cosmopolita. Rio de Janeiro, Renovar, 2004.

BARRETO, Vicente de Paulo. O fetiche dos direitos humanos e outros temas. São Paulo: Lumen Juris, 2010.

BENNANI, Aziza. Mundo latino e o mundo islâmico: um diálogo e uma interação imprescindíveis. In: ORO, Ari Pedro; DAL RI JÚNIOR, Arno (Orgs.). Islamismo e humanismo latino. Petrópolis, RJ: Vozes, Treviso, IT: Fondazione Cassamarca, 2004.

BUTLER, Judith. O limbo de Guatánamo. Novos estud. - CEBRAP, São Paulo, n. 77, mar. 2007.

DAVID, René. Os grandes sistemas do direito contemporâneo. 3. ed. São Paulo: Martins Fontes, 1996.

DAVUTOGLU, Ahmet. Cultura global versus pluralismo cultural: hegemonia civilizacional ou diálogo e interação entre civilizações. In: BALDI, César Augusto Baldi (Org.). Direitos humanos na sociedade cosmopolita. Rio de Janeiro, Renovar, 2004.

FOUCAULT, Michel. Em defesa da sociedade. São Paulo: Martins Fontes, 2002.

HIMMICH, Bensalem. A visão que a Europa Latina tem do Islã: momentos e desafios. In: ORO, Ari Pedro; DAL RI JÚNIOR, Arno (Orgs.). Islamismo e humanismo latino. Petrópolis, RJ: Vozes, Treviso, IT: Fondazione Cassamarca, 2004.

\footnotetext{
${ }^{9}$ Dr. Strangelove refere-se ao filme Dr. Strangelove or: How I Learned to Stop Worrying and Love the Bomb, de 1964, dirigido por Stanley Kubrick.
} 
JULLIEN, François. O diálogo entre culturas: do universal ao multiculturalismo. Tradução por André Telles. Rio de Janeiro: Jorge Zahar, 2009.

ORO, Ari Pedro; DAL RI JÚNIOR, Arno (Orgs.). Islamismo e humanismo latino. Petrópolis, RJ: Vozes, Treviso, IT: Fondazione Cassamarca, 2004.

PIOVESAN, Flávia. A universalidade e a indivisibilidade dos direitos humanos: desafios e perspectivas. In: BALDI, César Augusto Baldi (Org.). Direitos humanos na sociedade cosmopolita. Rio de Janeiro, Renovar, 2004.

RACHELS, James. Os elementos da filosofia moral. Tradução por Roberto Cavallari Filho. Barueri: Manole, 2006.

SANTOS, Boaventura de Sousa. Por uma concepção multicultural dos direitos humanos. In: BALDI, César Augusto Baldi (Org.). Direitos humanos na sociedade cosmopolita. Rio de Janeiro, Renovar, 2004.

SANTOS, Maria Helena de Castro. Exportação de democracia na política externa norteamericana no pós-Guerra-Fria: doutrinas e o uso da força. Rev. bras. polít. int. [online]. 2010, vol.53, n.1, p. 158-191.

SCHILLING, Voltaire. Ocidente x islã. 2. ed. Porto Alegre: L\&PM, 2003.

TOSTES, Ana Paula. Razões da intolerância na Europa Integrada. Dados. Rio de Janeiro, 2009, p. 335-376.

WALLERSTEIN, Immanuel Maurice. O universalismo europeu: a retórica do poder. São Paulo: Boitempo, 2007. 